\title{
Correction: A randomised clinical trial of methotrexate points to possible efficacy and adaptive immune dysfunction in psychosis
}

I. B. Chaudhry, M. O. Husain, A. B. Khoso, M. I. Husain @, M. H. Buch, T. Kiran, B. Fu, P. Bassett Q1, I. Qurashi, R. ur Rahman,

S. Baig, A. Kazmi, F. Corsi-Zuelli (1), P. M. Haddad, B. Deakin (1) and N. Husain

Correction to: Translational Psychiatry

https://doi.org/10.1038/s41398-020-01095-8

published online 30 November 2020

The original version of this article unfortunately contained an error in the COI section. Unfortunately, P. M. Haddad's COI statement was missed in the PDF although it was provided by the author. We apologize for this error. P. M. Haddad's COI statement should be: PMH has received personal fees from Janssen, Lundbeck, NewBridge Pharmaceuticals, Otsuka, and Sunovion outside the submitted work.

Published online: 01 September 2021 